\title{
On the state of health in inner London
}

\author{
R BALARAJAN
}

The egalitarian approach to health care delivery in the 1970s saw a change in allocating resources. The aim was equity in the access to health care between the "deprived" north west and the "affluent" south east. ' There has been widespread debate on the effects of such measures particularly on London. ${ }^{23}$ In the light of this the state of health in inner London as reflected in its recent mortality experience has been explored by investigating selected causes of death that closely or remotely could be influenced by effective health care.

\section{Methods}

Material published by the Office of Population Censuses and Surveys that included the 1981 census $^{4}$ and the mortality statistics for 1975-83 were used for the analysis. These years were selected because of the reorganisation of the health service boundaries in 1974 though the gradients reflect the outcome of influences over the decades. The areas of inner and outer London` were studied, along with the other conurbations-West Midlands, Greater Manchester, Merseyside, south Yorkshire, west Yorkshire, and Tyne and Wear. The four Thames health regions were studied as one unit, with the outer belt (after excluding inner and outer London) being examined separately. The analyses were also repeated separately by standard and health regions of England and Wales.

The 1981 census material for these areas was examined for social, demographic, and household characteristics. Trends in perinatal and infant mortality were studied along with selected causes of death that could be influenced by appropriate health care.

These included infectious and parasitic diseases; tuberculosis, including its late effects; cancer of trachea, bronchus, and lung; cancer of cervix uteri; anaemias; chronic rheumatic heart disease; hypertensive disease; ischaemic heart disease; pneumonia; bronchitis; emphysema and asthma; intestinal obstruction and hernia; chronic liver disease and cirrhosis; external causes of injury; and suicide. This list is not comprehensive, and the causes vary in the extent to which they could be influenced by health care and in the lag period for shifts in mortality gradients to become evident. The trends over time in these areas were examined separately for the sexes by computing age standardised mortality ratios with the 1975 England and Wales age, sex, and cause specific mortality rates as standard in order to effect comparison with national trends. Similar ratios were also computed for the respective geographical areas for the period 1979-83 inclusive, using the respective English rates of each individual year as standard. This was done to examine differential levels of area mortality without being handicapped by small numbers.

*As defined by the census division of the Office of Population Censuses and Surveys in the 1981 census.

Medical Department, South West Thames Regional Health Authority, London W2 3QR

R BALARAJAN, MB, MFCM, regional specialist in community medicine

Correspondence to: South West Thames Regional Health Authority, 40 Eastbourne Terrace, London W2 3QR.
This paper deals with inner and outer London, the outer belt of the Thames health regions (outer Thames), and the six English conurbations.

\section{Results}

In the 1981 census $2 \cdot 4$ million- $15 \%$ of the population of the south east region-were enumerated as usually resident in inner London, in an area of 321 square kilometres. Greater London, the largest conurbation, has more than twice the population of the second largest conurbation-the West Midlands. Inner London, however, if considered as a conurbation in its own right, is the third largest after the West Midlands and Greater Manchester.

The demographic and social characteristics of those resident in inner London contrast markedly within the south east. Inner London has more immigrants, who amount to almost a quarter of its population, and almost a fifth of the heads of households are in the lower social classes (IV and V).

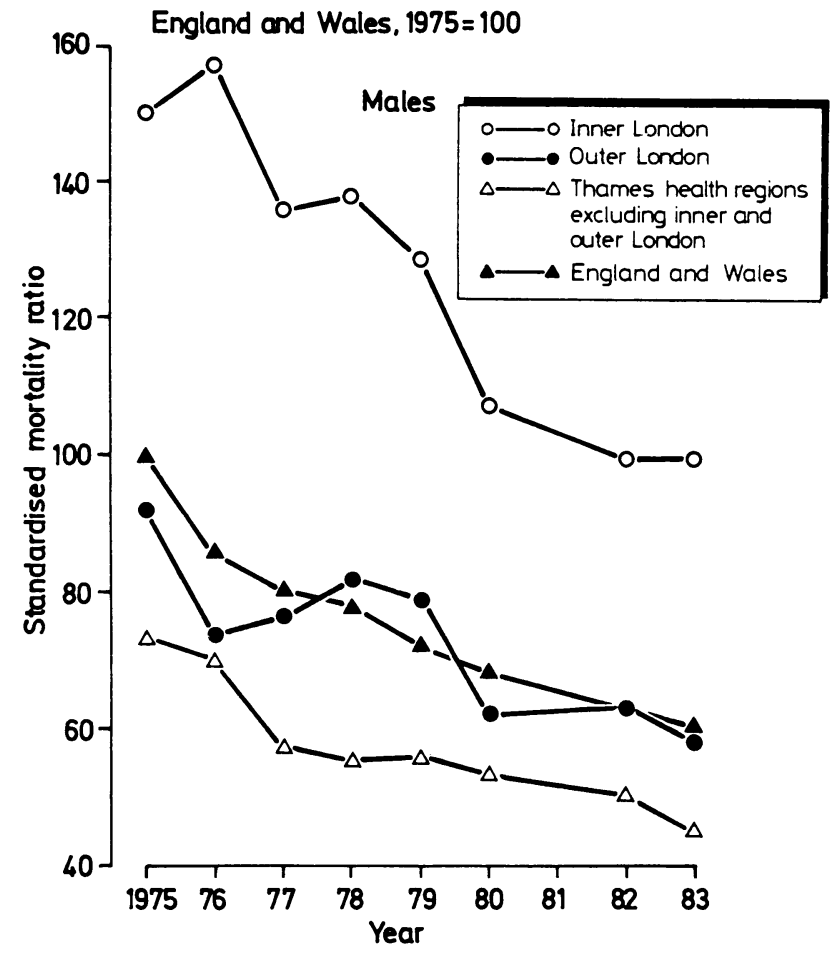

FIG 1-Trends in mortality from infective and parasitic diseases in men, 1975-83.

Similarly, unemployment and single person households, including pensioners living alone, are much higher in inner London. The percentage of households with pensioners living alone is higher in inner London than in any other conurbation, and inner London is second only to the West Midlands and Merseyside in the percentage of the population in households with the head in social classes IV and V.

Inner London's housing features poorly, with $43 \%$ of the households rented from local authorities in contrast to $27 \%$ in the south east. There are more persons to a room in inner London than in any other conurbation. A 
lack of amenities, such as a bath or shower, is also proportionately higher in inner London than in some of the areas with which it competes for resources.

Levels of perinatal and infant mortality have been consistently higher in inner London than outer London or outer Thames. There is a differential improvement evident for both perinatal and infant mortality in outer London. Perinatal mortality in inner London is, however, lower than in all other conurbations with the exception of Merseyside. Infant mortality in inner London is higher than in Merseyside, south Yorkshire, and Tyne and Wear.

Trends in mortality from infective and parasitic diseases showed marked geographical variations. Though the overall trend was on the decline, the gradients differed with higher levels in inner London for both men (fig 1) and women. The levels in the conurbations of England were much lower than those in inner London (table I). Death from tuberculosis featured significantly within this category and was again much higher in men and women in inner London. The levels in the other conurbations were lower than that in inner London.

Mortality from lung cancer, though declining gradually in men over the past few years, tended to rise in women. The rates for outer London were higher than those for outer Thames, but those people living in inner London suffered much higher rates, higher than those of most conurbations. Deaths from cancer of the cervix were also higher in inner London compared with outer London and outer Thames, but levels in the other conurbations were greater, with the exception of the West Midlands.

The mortality attributed to hypertension in men was higher in inner London than in any other conurbation though the rate in women was second to that in the West Midlands (table II). Deaths from ischaemic heart disease were lower than expected in inner and outer London. Chronic rheumatic disease, however, claimed more lives in inner London than in outer London or in any other conurbation, the only exceptions being Greater Manchester and south Yorkshire, where the rates for women were higher.

The death rate from pneumonia was higher for men (fig 2) and women in inner London. Levels of mortality higher than in inner London were seen only in Merseyside and the West Midlands. Deaths from bronchitis, emphysema, and asthma have declined in both sexes since 1975 but with marked geographical variations, the rates being lower in outer London and outer Thames, in contrast to inner London. Among women levels in the

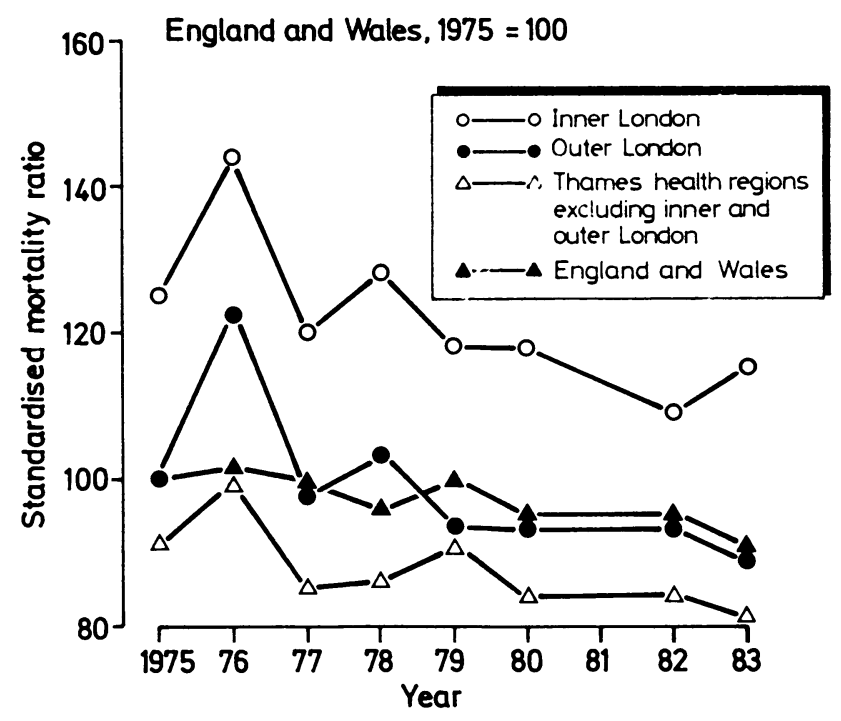

FIG 2-Trends in mortality from pneumonia in men, 1975-83.

TABLE I-Levels of mortality by cause, sex, and area of residence, standardised mortality ratios 1979-83 (observed deaths in parentheses)

\begin{tabular}{|c|c|c|c|c|c|c|}
\hline & & $\begin{array}{c}\text { Infectious and } \\
\text { parasitic diseases }\end{array}$ & $\begin{array}{c}\text { Tuberculosis and } \\
\text { late effects }\end{array}$ & $\begin{array}{c}\text { Cancer of } \\
\text { trachea, bronchus, and lung }\end{array}$ & $\begin{array}{l}\text { Cancer of } \\
\text { cervix uteri }\end{array}$ & Anaemias \\
\hline \multirow[t]{2}{*}{ Inner London } & M & $172 \star(495)$ & $221^{\star}(286)$ & $126^{\star}(8433)$ & - & $108(100)$ \\
\hline & $\mathrm{F}$ & $132 \star(334)$ & $169 \star(123)$ & $140^{\star}(3129)$ & $100 \quad(515)$ & 89 (176) \\
\hline \multirow[t]{2}{*}{ Outer London } & M & $103(506)$ & 106 & $101(11653)$ & - & $86(136)$ \\
\hline & $\mathrm{F}$ & $104(436)$ & $134^{\star}(163)$ & $108^{\star}(4085)$ & $75^{\star}(660)$ & $82^{\star}(260)$ \\
\hline \multirow{2}{*}{ Greater Manchester } & M & $108(310)$ & 115 (147) & $117^{\star}(7714)$ & - & $111 \quad(99)$ \\
\hline & $\mathrm{F}$ & $96(239)$ & 113 (82) & $108^{\star}(2450)$ & $121^{\star} \quad(628)$ & $153^{\star}(279)$ \\
\hline \multirow[t]{2}{*}{ Merseyside } & M & $116^{\star}(192)$ & 119 & $130^{\star}(4958)$ & - & $120 \quad 62)$ \\
\hline & $\mathrm{F}$ & $114(169)$ & $123 \quad(53)$ & $139 \star(1870)$ & $145^{\star}(448)$ & $133^{\star}(147)$ \\
\hline \multirow[t]{2}{*}{ South Yorkshire } & $M$ & $83^{\star}(125)$ & $93 \quad 63)$ & $111^{\star}(3922)$ & - & $97 \quad(46)$ \\
\hline & $\mathrm{F}$ & 99 (119) & $70 \quad(25)$ & $93^{\star}(1034)$ & $115^{\star}(296)$ & $98 \quad(85)$ \\
\hline \multirow[t]{2}{*}{ Tyne and Wear } & M & $140 *(176)$ & $152^{\star}(89)$ & $142^{\star}(4290)$ & - & 116 \\
\hline & $\mathrm{F}$ & $114(126)$ & $107 \quad(35)$ & $141^{\star}(1450)$ & $124^{\star}(292)$ & 112 (91) \\
\hline \multirow[t]{2}{*}{ West Midlands } & M & $123^{\star}(363)$ & $138^{\star}(181)$ & $112^{\star}(7574)$ & - & $143^{\star}(127)$ \\
\hline & $\mathrm{F}$ & $114^{\star}(272)$ & $125 *(87)$ & $90 *(1951)$ & $93 \quad(476)$ & $151^{\star}(254)$ \\
\hline \multirow{2}{*}{ West Yorkshire } & M & $113^{\star}(261)$ & 116 (119) & $107^{\star}(5658)$ & - & $105 \quad(76)$ \\
\hline & $\mathrm{F}$ & $98(195)$ & $97 \quad(56)$ & 104 (1855) & $129^{\star} \quad(529)$ & 97 (146) \\
\hline \multirow[t]{2}{*}{ Thames health regions excluding Greater London } & $M$ & $80^{\star}(651)$ & $70^{\star}(259)$ & $89 \star(16872)$ & - & $98 \quad(269)$ \\
\hline & $\mathrm{F}$ & $89^{\star}(619)$ & $66^{\star}(133)$ & $94^{\star} \quad(5852)$ & $82^{\star}(1171)$ & $88^{\star}(479)$ \\
\hline
\end{tabular}

England $=100$ for each individual year. ${ }^{*} \mathrm{p} \leqslant 0 \cdot 05$.

TABLE II-Levels of mortality by cause, sex, and area of residence, standardised mortality ratios 1979-83 (observed deaths in parentheses)

\begin{tabular}{|c|c|c|c|c|c|}
\hline & & Chronic rheumatic heart disease & Hypertensive disease & Ischaemic heart disease & Pneumonia \\
\hline \multirow[t]{2}{*}{ Inner London } & M & $145^{\star}(308)$ & $132^{\star}(799)$ & $92^{\star}(20370)$ & $120^{\star}(6588)$ \\
\hline & $\mathrm{F}$ & $136^{\star}(779)$ & $114^{\star}(925)$ & $88^{\star}(15529)$ & $113^{\star}(10396)$ \\
\hline \multirow[t]{2}{*}{ Outer London } & $M$ & $100 \quad(366)$ & $112^{\star}(1167)$ & $93^{\star}(35463)$ & $98 \quad(9291)$ \\
\hline & $\mathrm{F}$ & $98 \quad(943)$ & $109 \star(1436)$ & $90^{\star}(25968)$ & $106^{\star}(15506)$ \\
\hline \multirow[t]{2}{*}{ Greater Manchester } & $\mathbf{M}$ & $108 \quad(227)$ & $97 \quad(574)$ & $119 \star(25992)$ & $107^{\star}(5524)$ \\
\hline & $\mathrm{F}$ & $146^{\star}(832)$ & $100 \quad(767)$ & $121^{\star}(20309)$ & $100 \quad(8188)$ \\
\hline \multirow[t]{2}{*}{ Merseyside } & $M$ & $123^{\star}(150)$ & $96 \quad(330)$ & $111^{\star}(13990)$ & $136^{\star}(4118)$ \\
\hline & $\mathrm{F}$ & $131^{\star}(445)$ & $77^{\star}(356)$ & $110^{\star}(11141)$ & $119^{\star}(6003)$ \\
\hline \multirow{2}{*}{ South Yorkshire } & M & $134^{\star}(150)$ & $96 \quad(305)$ & $107^{\star}(12517)$ & $86^{\star}(2417)$ \\
\hline & $\mathrm{F}$ & $137^{\star}(379)$ & $99 \quad(360)$ & $112^{\star}(9009)$ & $91^{\star}(3481)$ \\
\hline \multirow[t]{2}{*}{ Tyne and Wear } & $M$ & $97 \quad(94)$ & $86^{\star}(233)$ & $115 *(11481)$ & $118^{\star}$ \\
\hline & $\mathrm{F}$ & $107 \quad(274)$ & $94 \quad(321)$ & $122^{\star}(9173)$ & $107^{\star}(3894)$ \\
\hline \multirow[t]{2}{*}{ West Midlands } & M & $129^{\star}(281)$ & $119^{\star}(715)$ & $102 \star(22823)$ & $130^{\star}(6594)$ \\
\hline & $F$ & $116^{\star}(627)$ & $120^{\star}(847)$ & $103 *(16038)$ & $120^{\star}(8940)$ \\
\hline \multirow[t]{2}{*}{ West Yorkshire } & $M$ & $106 \quad(179)$ & $97 \quad(465)$ & $120^{\star}(20990)$ & $107^{\star}(4581)$ \\
\hline & $\mathrm{F}$ & $128^{\star}(578)$ & $92^{\star}(573)$ & $127^{\star}(17311)$ & $103^{\star}(7030)$ \\
\hline \multirow[t]{2}{*}{ Thames health regions excluding Greater London } & $\mathbf{M}$ & $84^{\star}(502)$ & $95 \star(1670)$ & $90^{\star}(57706)$ & $89 \star(14889)$ \\
\hline & $\mathrm{F}$ & $72 \star(1148)$ & $102(2261)$ & $88 \star(42841)$ & $90 \star(22622)$ \\
\hline
\end{tabular}

England $=100$ for each individual year. * $p \leqslant 0.05$. 
TABLE III-Levels of mortality by cause, sex, and area of residence, standardised mortality ratios 1979-83 (observed deaths in parentheses)

\begin{tabular}{|c|c|c|c|c|c|c|}
\hline & & $\begin{array}{c}\text { Bronchitis, } \\
\text { emphysema, and asthma }\end{array}$ & $\begin{array}{c}\text { Intestinal obstruction and } \\
\text { hernia }\end{array}$ & $\begin{array}{l}\text { Chronic liver disease } \\
\text { and cirrhosis }\end{array}$ & $\begin{array}{c}\text { External causes of } \\
\text { injury }\end{array}$ & Suicide \\
\hline \multirow[t]{2}{*}{ Inner London } & $M$ & $129 *(4450)$ & $109(213)$ & $173^{\star}(490)$ & $136^{\star}(4076)$ & $162^{\star}(1536)$ \\
\hline & $\mathbf{F}$ & $138 \star(2164)$ & $113^{\star}(378)$ & $145^{\star}(380)$ & $123^{\star}(2716)$ & $150^{\star}(906)$ \\
\hline \multirow{2}{*}{ Outer London } & $M$ & $100(5917)$ & $92(309)$ & $103(502)$ & $87 \star(4276)$ & $95 \star(1490)$ \\
\hline & $\mathrm{F}$ & $113^{\star}(2894)$ & $95(509)$ & $99(443)$ & $84 \star(3017)$ & $102(1032)$ \\
\hline \multirow{2}{*}{ Greater Manchester } & $M$ & $122^{\star}(4046)$ & $115^{\star}(217)$ & $117^{\star}(337)$ & $103(3037)$ & $109^{\star}(1021)$ \\
\hline & $\mathrm{F}$ & $135^{\star}(2020)$ & $109(336)$ & $117^{\star}(313)$ & $115^{\star}(2442)$ & $127^{\star}(762)$ \\
\hline \multirow[t]{2}{*}{ Merseyside } & $M$ & $119^{\star}(2292)$ & $94(103)$ & $122 \star(202)$ & 102 (1741) & 92 (495) \\
\hline & $\mathrm{F}$ & $132 \star(1196)$ & $113(210)$ & $126^{\star}(201)$ & $106 *(1351)$ & $105 \quad(372)$ \\
\hline \multirow[t]{2}{*}{ South Yorkshire } & $M$ & $145 *(2599)$ & $99(100)$ & $81^{\star}(122)$ & $92^{\star}(1400)$ & $90^{\star}(435)$ \\
\hline & $\mathrm{F}$ & $130^{\star}(940)$ & $101(146)$ & $79 *(105)$ & $84^{\star}(870)$ & $88 *(264)$ \\
\hline \multirow[t]{2}{*}{ Tyne and Wear } & $M$ & $108^{\star}(1637)$ & $105 \quad(90)$ & $148^{\star}(195)$ & 99 (1312) & $112^{\star}(471)$ \\
\hline & $\mathrm{F}$ & $120^{\star}(810)$ & 96 (131) & 108 (132) & $104(984)$ & 102 (278) \\
\hline \multirow{2}{*}{ West Midlands } & M & $121^{\star}(4030)$ & $109(205)$ & $127 \star(384)$ & $92 \star(2817)$ & $91 *(880)$ \\
\hline & $\mathrm{F}$ & $106^{\star}(1488)$ & $83^{\star}(235)$ & $114^{\star}(300)$ & $114^{\star}(2330)$ & $90^{\star}(537)$ \\
\hline \multirow[t]{2}{*}{ West Yorkshire } & $M$ & $129^{\star}(3503)$ & $110(170)$ & $90(204)$ & $111^{\star}(2612)$ & $111^{*}(824)$ \\
\hline & $\mathrm{F}$ & $128^{\star}(1550)$ & 107 (269) & 92 (194) & $120^{\star}(2043)$ & $120^{\star}(567)$ \\
\hline \multirow[t]{2}{*}{ Thames health regions excluding Greater London } & M & $81 \star(8223)$ & $94(550)$ & $78^{\star}(617)$ & $87^{\star}(7059)$ & $94^{\star}(1772)$ \\
\hline & $\mathrm{F}$ & $80^{\star}(3469)$ & $99(904)$ & $91^{\star}(665)$ & $82^{\star}(4888)$ & $96^{\star}(1091)$ \\
\hline
\end{tabular}

England $=100$ for each individual year.

${ }^{\star} \mathrm{p} \leqslant 0.05$.

conurbations were lower than in inner London, though in men higher levels were seen in south Yorkshire (table III).

Deaths attributed to cirrhosis were higher in inner London than in any other conurbation with standardised mortality ratios of 173 and 145 respectively for men and women. Deaths from accidents, violence, and poisoning showed marked geographical variations. Though the rates for the country as a whole were on the decline, rates for inner London showed a gradual increase since 1977 (fig 3). The levels in both sexes were higher in inner London than in any conurbation. Suicides, on the other hand, were on the increase in men in all geographical areas, the rates in inner London being the highest. The rates for women increased until around 1980, when they tended to decline in most geographical areas. Deaths from suicide were much higher in inner London than in any conurbation but no excess was evident in outer London.

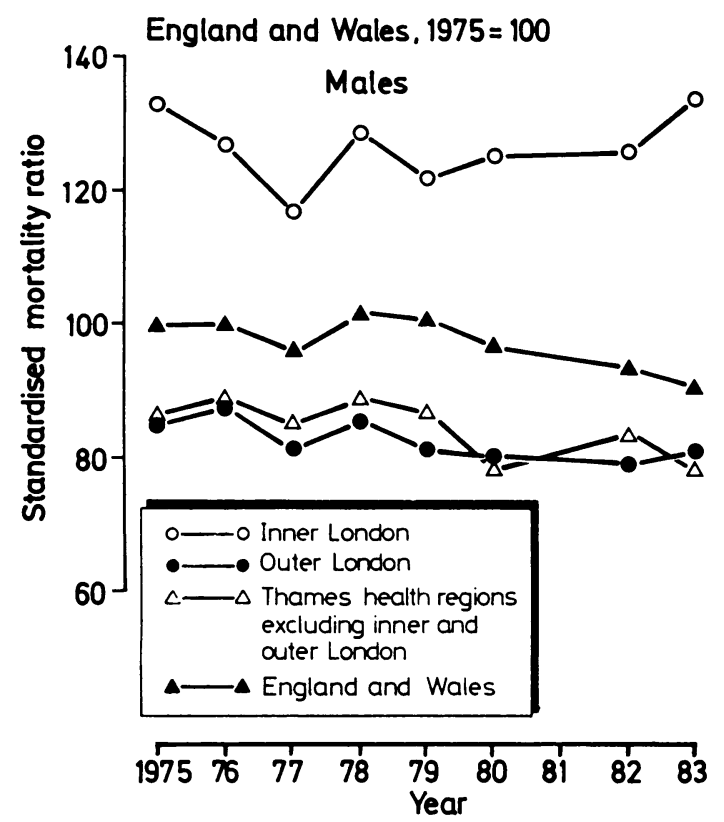

FIG 3-Trends in mortality from external causes of injury and poisoning in men, $1975-83$.

\section{Discussion}

Mortality has been used historically to monitor the health of a nation as comparable health status indicators are not readily available. ${ }^{5}$ Mortality experience is the tip of the iceberg in terms of ill health and reflects the cumulative multifactorial interaction of social and biological factors over time. The effectiveness of a service such as health care ought to be evaluated by different outcome measures linked to corresponding objectives. In this analysis a global evaluation has been attempted by studying selected causes of death that could be argued to be amenable to influence by a sensitive and effective health care system. If differential mortality is measured against reference gradients the findings reflect inequalities in terms of health. The list of causes considered is not comprehensive and vary in the lag period for demonstrable shifts to appear in terms of mortality. Though the recent mortality experience has been examined in this paper, the trends and differentials reflect the cumulative impact of health care over the past few decades.

In most of the causes examined trends have been on the decline in most geographical regions, with the notable exception of lung cancer in women and suicide. The important findings, however, are the persistent differentials between the areas of Greater London -namely, inner and outer London. The rates in inner London remained much higher than those of outer London, which were very much in line with the rates for the outer Thames areas. Inner London also had higher levels of mortality than the other conurbations for many preventable diseases. Though some variation in certification is possible, this is unlikely to explain the extent of the differences in mortality. In this context inner London has more than its fair share of problems relating to primary care, as was highlighted in the Acheson report. ${ }^{6}$

Social class variations in the levels of mortality are well established, ${ }^{78}$ and other social variables, such as housing tenure and access to cars, are also known to be sensitive discriminants of mortality. ${ }^{9}$ Variations in health status and health service utilisation have also been shown among different socioeconomic groups. In many ways inner London is distinctly more socially disadvantaged than the surrounding south east especially outer London. It has many indicators of need that are worse than those in the largest conurbations in the north.

Despite the decline in its population inner London is still larger than three other RAWP gaining regional health authorities. The scale and the extent of multiple deprivation in inner London are in many ways unique. Its poor indicators, however, are masked in the Thames health regions as four regions share inner London for management purposes. Facilities and resources have centred in London, resulting in an element of overprovision. In addition to providing services for its own residents, however, a major contribution has gone towards meeting regional and national needs, undergraduate and postgraduate requirements, and, more importantly, providing leadership in research and development in medicine. The extent to which these facilities and resources are reduced and over what period should be carefully evaluated and balanced against the differential effects on total health care to its own residents on the one hand and the remaining needs-regional and national, undergraduate and postgraduate, research and development - on the other. 
The requirements of inner London are different from and more complex than those of the rest of the Thames regions and it would be increasingly difficult for the Thames regions to be sensitive to its needs-especially in times of recurrent economic stringencybecause the process of resource allocation was conceived within a framework of expanding resources. The aim was for the less affluent regions to take a bigger share of the whole without curtailing the funds to meet the needs of the other better endowed ones. Shifts towards a comprehensive and effective service for the community, as advocated recently, ${ }^{1011}$ are unlikely to be achieved in inner London while it is on the losing end of RAWP.

\section{NEED FOR CONTINUOUS EVALUATION}

Though the principle of equity is unquestionable, the basis for reallocation, the cumulative effects of the application of a formula, and the timetable are all open to debate and need continuous evaluation. If linked to different population sizes and mix and to geographical boundaries the allocation process will lead to different weightings, and the present process is not sensitive to inner London's complex needs. The introduction of another formula could produce difficulties, but this should not hinder a search for alternatives, as mortality gradients are unlikely to converge within the life of a strategic planning cycle. So the open ended application of such differentials cannot be rational if continued indefinitely into the future. If different concepts to those introduced in the national RAWP formula were to be adopted by regional health authorities these would lead to a further disparity after subregional allocations. In some regions mortality is used as in the national RAWP formula, whereas in others it is modified or even dropped. ${ }^{12}$ Other measures, such as the distribution of socioeconomic groups, the elderly living alone, and the different ethnic groups, are worthy of consideration in allocating resources. A major determinant should be morbidity levels estimated through sample surveys of the population. The unit of allocation for both primary and secondary health care also deserves more examination so that the principles advocated nationally are applied uniformly without further distortion.

In 1948 the National Health Service was given broad objectives not only to provide preventive and therapeutic comprehensive health care but also to promote the nation's physical and mental well-being. ${ }^{13}$ Recently greater emphasis has been placed on efficiency at the level of secondary care than on total health care. Planning in many spheres is not tuned to the needs of the community but modelled on historic demands or global norms. How appropriate are the present health care planning models, especially as applied to inner London? A further deterrent in providing a comprehensive service is the separate allocation and planning process for both the health and social services sectors, despite the determinants of need being in many instances related and the outcomes often interdependent.

The fractionation of inner London has aided the geographical placement of medical schools in each region but has hampered concerted efforts to resolve the overwhelming needs of inner London. The true picture of London's needs has also been distorted by the better indicators of the affluent south east. Inner London's higher levels of mortality from various causes, many of them preventable, the size and diversity of its population, and its differential needs should prompt debate about a new planning process for the area. Its $2 \cdot 4$ million people must be grouped as a separate entity if the special medical and social needs of the area are to be met and the high standards of its centres of excellence maintained.

I should like to thank Dr J S A Ashley, department of community health, London School of Hygiene and Tropical Medicine; Mr L Bulusu, population division, Office of Population Censuses and Surveys; Dr P O Goldblatt, social statistics research unit, City University; Dr E Vincent, Wandsworth District Health Authority, and Dr D Wild, South West Thames Regional Health Authority, for their helpful comments; and Mrs Anne Aykiran for typing the manuscript.

Additional statistical information used in the study is available from the author.

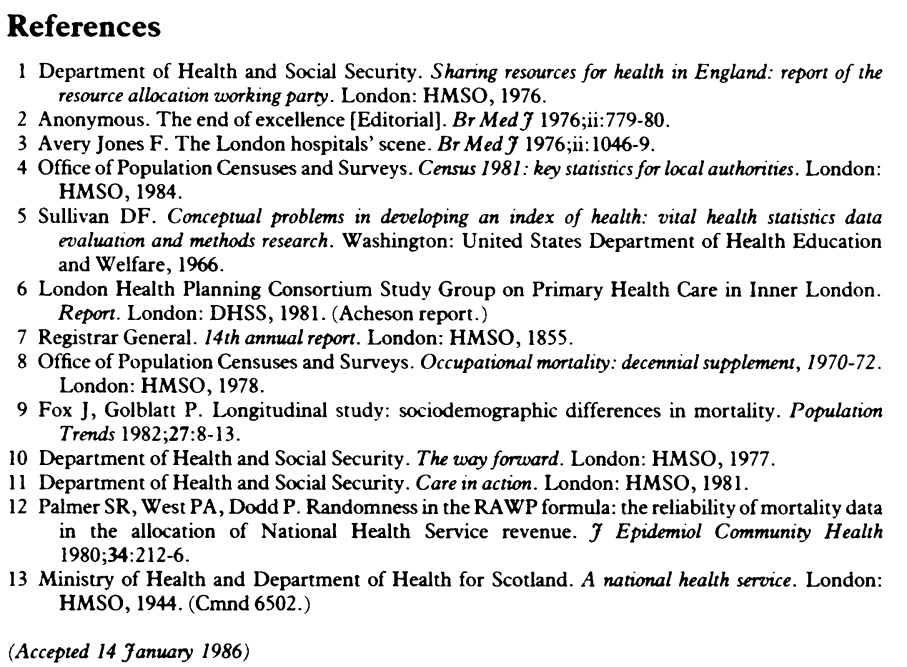

References

A

Avery Jones F. The London hospitals' scene. Br Med F 1976;ii: 1046-9.

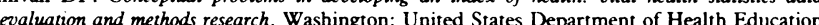
and Welfare, 1966

(1970-72.

, Golblat P. Longitudinal study: sociodemographic differences in mortality. Population

0 Department of Healh and Social Security. The way forward. London: HMSO, 1977.

11 Department of Health and Social Security. Care in action. London: HMSO, 1981.

Palmer SR, West PA, Dodd P. Randomness in the RAWP formula: the reliability of mortality data 1980;34:212-6.

HMSO, 1944. (Cmnd 6502.)

(Accepted 14 fanuary 1986)

\section{GMC professional conduct committee}

At a meeting of the professional conduct committee of the General Medical Council, which met in the week beginning $3 \mathrm{March}$, the name of Dr Tom Mutazindwa of Enfield was erased from the Register. Dr Mutazindwa had been convicted in December 1984 on a charge of being knowingly concerned in the fraudulent evasion of the prohibition on importation of a controlled drug and he was sentenced to 18 months' imprisonment.

Dr Philip Pottage of Edinburgh and Dr Anthony George Collington of Sheffield were found guilty of serious professional misconduct and they were suspended for 12 months. Dr Pottage had abused his position as a registered medical practitioner wrongfully to misappropriate for his own use supplies of cocaine solution from the hospital's supply of controlled drugs. Dr Collington had committed adultery with a patient.

\section{Scottish health statistics}

More general practitioners and hospital staff were working in the National Health Service in Scotland in 1984 and the number of qualified nursing staff reached an all time record. This is reported in Scottish Health Statistics 1984 published by the Common Services Agency. Scotland had 3529 general practitioners and an average list size of 1704. Just over 5800 hospital and community services medical staff were employed and the total number of qualified nurses increased to over 28000 . The drugs bill continued to rise and the 38 million prescriptions dispensed in 1984 represented an average of seven per patient. The total cost of the drugs bill was $£ 181 \mathrm{~m}$, though charges reduced the net cost to $£ 167 \mathrm{~m}$. The general dental service administered $2.8 \mathrm{~m}$ courses of treatment. The report says that the ambulance service carried more patients - over two million and the air ambulance service carried 978 patients, flying over 290000 miles.

\section{Fees' increases}

We reported on 15 March (p 778) that the council had approved increases in fees that it recommends on the advice of the private practice and professional fees committee for medical services outside the National Health Service for which no agreed fees exist. Details of the revised fees are available from regional and national offices and members should quote their 1986 membership number and the reference "FS 34." 